PNL-SA-24698

\title{
ORGANIC DESTRUCTION TO ENHANCE THE SEPARATION OF STRONTIUM IN RADIOACTIVE WASTES
}
A. J. Schmidt
A. H. Zacher
M. R. Elmore
T. R. Hart
R. J. Orth
G. G. Neuenschwander
E. O. Jones
J. C. Poshusta

October 1994

Presented at the

Metals and Materials Waste Reduction Recovery, and Remediation Symposium

October 2-6, 1994

Rosemont, Illinois

Prepared for

the U.S. Department of Energy

under Contract DE-AC06-76RLO 1830

Pacific Northwest Laboratory
Richland, Washington 99352

\section{DISCLAIMER}

This report was prepared as an account of work sponsored by an agency of the United States Government. Neither the United States Government nor any agency thereof, nor any of their employees, makes any warranty, express or implied, or assumes any legal liability or responsibility for the accuracy, completeness, or usefulness of any information, apparatus, product, or process disclosed, or represents that its use would not infringe privately owned rights. Reference herein to any specific commercial product, process, or service by trade name, trademark, manufacturer, or otherwise does not necessarily constitute or imply its endorsement, recommendation, or favoring by the United States Government or any agency thereof. The views and opinions of authors expressed herein do not necessarily state or reflect those of the United States Government or any agency thereof. 


\section{DISCLAIMER}

Portions of this document may be illegible in electronic image products. Images are produced from the best available original document. 


\title{
Organic Destruction to Enhance the Separation of Strontium in Radioactive Wastes
}

\author{
A. J. Schmidt, M. R. Elmore, R. J. Orth, E. O. Jones, \\ A. H. Zacher, T. R. Hart, G. G. Neuenschwander, J. C. Poshusta \\ Pacific Northwest Laboratory \\ P.O. Box 999 \\ Richland, Washington 99352
}

\begin{abstract}
A low-temperature $\left(300^{\circ} \mathrm{C}\right.$ to $\left.375^{\circ} \mathrm{C}\right)$ hydrothermal organic destruction process is being evaluated to help facilitate the removal of complexed radioactive species from bulk liquid components in Hanford tank waste. The work focuses on hydrothermal processing to destroy organic compounds that contribute to waste safety issues and organic complexants that promote the solubility of radioactive constituents such as ${ }^{90} \mathrm{Sr}$ and ${ }^{241} \mathrm{Am}$. For the studies discussed here, testing was conducted using a nonradioactive Hanford tank waste simulant. The relative destruction rates of a variety of organic compounds known to be present in Hanford tank waste were evaluated. In addition, the tendency for these organic compounds to complex strontium and the effect of hydrothermal treatment on strontium removal were investigated.
\end{abstract}


Environmental remediation efforts at the Hanford Site include safely managing and disposing of high-level (HLW), transuranic (TRU), and low-level radioactive wastes (LLW) currently being stored in underground tanks. Certain classes of tanks at the Hanford Site are considered highest priority with respect to safety: the explosive gas $\left(\mathrm{H}_{2}\right)$ generating tanks, the organic tanks, and the ferrocyanide tanks. The problems associated with these types of tanks can be mitigated if the organic material and/or ferrocyanide could be destroyed or removed. Additionally, deactivation or destruction of complexing organics in tank wastes would eliminate organic species that can reduce the efficiency of radionuclide (e.g., ${ }^{90} \mathrm{Sr}$ ) separation processes, such as ion exchange, solvent extraction, and precipitation.

Researchers at Pacific Northwest Laboratory (PNL) are developing a low-temperature hydrothermal process (HTP) to help mitigate safety and disposal and processing issues created by the presence of organics in Hanford tank wastes. ${ }^{(1)}$ HTP is a thermal-chemical autogenous processing method that is typically operated between $300^{\circ} \mathrm{C}$ and $375^{\circ} \mathrm{C}$ and at approximately $3000 \mathrm{psig}$. The low-temperature HTP work at PNL is integrated with complementary work at Los Alamos National Laboratory in which processing is being conducted at higher temperatures $\left(375^{\circ} \mathrm{C}\right.$ to $550^{\circ} \mathrm{C}$ ) and pressures $(4000$ to $15000 \mathrm{psig}){ }^{(2,3)}$ Under the HTP conditions, organics react with oxidants, such as nitrite and nitrate, that are already present in the waste. Actual processing of the tank waste with HTP would take place in a plug-flow, tubular reactor or a continuous stirred-tank reactor system designed to accommodate the temperature, pressure, gas generation, and heat release associated with decomposition of the reactive species.

Part of the PNL work involves batch testing with a nonradioactive tank waste simulant to provide a basis for determining the effects of HTP treatment on organic destruction and strontium removal. This paper discusses the batch testing and gives relative organic destruction rates and the fate of strontium determined from the studies.

These studies were designed to support future testing with actual radioactive solutions. Presumably if the organic complexants are destroyed or deactivated, complexed metals, such as ${ }^{90} \mathrm{Sr}$, will be released from solution. Thus, HTP treatment followed by filtration may be an effective means of removing radioactive constituents, such as ${ }^{90} \mathrm{Sr}$ from solution. In some cases, even with the destruction or deactivation of organic complexants, the ${ }^{90} \mathrm{Sr}$ concentration in solution may still be too high to meet low-level disposal requirements. However, upon destruction or deactivation of the organic complexants via HTP, further downstream processing such as ion exchange or solvent extraction may be more effective in removing residual amounts of ${ }^{90} \mathrm{Sr}$ and other radioactive constituents, such as ${ }^{241} \mathrm{Am}$.

\section{Background}

For over 15 years, PNL researchers have been investigating the use of high-pressure liquid water at elevated temperatures as a processing environment to destroy and convert organic compounds. This work was the subject of a recent review article. ${ }^{(4)}$ Also, some recent work involving the catalytic destruction of organics has been described. ${ }^{(5,6,7)}$ Based on similar principles, low-temperature HTP is being investigated at PNL as a potential 
process for converting and destroying organics present in Hanford tank wastes. ${ }^{(1)}$ HTP utilizes the oxidants already present in the Hanford tank wastes. By converting or destroying organics, the potential safety hazards are eliminated and more efficient downstream processing to remove radionuclides of concern (e.g., ${ }^{90} \mathrm{Sr}$ and ${ }^{241} \mathrm{Am}$ ) can be accomplished.

From recent testing, ${ }^{(1)}$ the destruction efficiency of low-temperature HTP has been established for organics in simulant tank waste using batch, continuous bench-scale, and pilot-scale test systems. The majority of the testing was conducted at 3:1 (v:v) ratios of water to Hanford Tank 241-SY-101 (101-SY) simulant ${ }^{(8)}$ containing EDTA as the organic source. Based on the results of experiments performed in a 1-L continuous flow tubular reactor, it was determined that at $365^{\circ} \mathrm{C}, 3000 \mathrm{psig}$, and a 7 -min residence time, the total organic carbon (TOC) in the simulant could be reduced by $80 \%$. This level of organic destruction is sufficient to meet the organic destruction criterion established by the U.S. Department of Energy (i.e., reduction of the TOC level to less than $1556 \mathrm{ppm}$ TOC in a tank waste to meet safety and downstream processing criteria). If needed, higher levels of TOC reduction can be achieved by increasing the residence time and/or increasing the reactor temperature.

A kinetic expression was developed for EDTA destruction from continuous testing conducted in the temperature range of approximately $300^{\circ} \mathrm{C}$ to $375^{\circ} \mathrm{C}$. EDTA destruction was found to be approximately first order with respect to both nitrite and EDTA concentration (i.e., second order overall), and the activation energy was found to be 24.7 $\mathrm{kcal} / \mathrm{mol}$.

The following chemical reactions were proposed for the destruction of EDTA:

$$
\begin{aligned}
& \mathrm{C}_{10} \mathrm{O}_{8} \mathrm{~N}_{2} \mathrm{H}_{12}{ }^{-4}+6 \mathrm{NO}_{2}^{-} \rightarrow 5 \mathrm{C}_{2} \mathrm{O}_{4}^{-2}+2 \mathrm{NH}_{3}+3 \mathrm{~N}_{2}+3 \mathrm{H}_{2} \\
& 5 \mathrm{C}_{2} \mathrm{O}_{4}^{-2}+10 \mathrm{OH}^{-} \longrightarrow 10 \mathrm{CO}_{3}^{-2}+5 \mathrm{H}_{2}
\end{aligned}
$$

In the reaction sequence, oxalate is formed by the reaction between nitrite and EDTA, and then oxalate further decomposes to carbonate. From extensive bench-scale testing, it was observed that an average 0.78 mole of nitrite is consumed for every mole of EDTA carbon that is destroyed. This is in fairly good agreement with, although consistently higher than, that predicted by Reaction 1 . This observation indicates that although the majority of the nitrite is being consumed in the EDTA destruction process, small amounts of nitrite are also being consumed in other reactions. Testing results also showed that smaller amounts of hydrogen gas were being produced than would be predicted from Reactions 1 and 2, and substantial amounts of nitrous oxide were produced. Thus, some of the nitrite may be reduced to nitrous oxide by reaction with hydrogen. It was also observed that nitrate levels change minimally during the destruction process in the presence of comparable amounts of nitrite. This suggests that nitrate is playing a minor role in the destruction of organic carbon or the production of nitrous oxide.

Recently, batch tests, using 101-SY simulant were conducted to determine the degree of organic destruction necessary to remove strontium from solution. Testing was conducted for various organic compounds that are expected to exist in Hanford tank waste. The results of these tests are presented in this paper. 


\section{Experimental}

The equipment, procedures, reagents, and analytical techniques used for the batch testing are described below.

\section{Equipment}

Testing was conducted in a $1-\mathrm{L}$ batch reactor manufactured by Autoclave Engineers. A diagram of the reactor system is given in Figure 1. The reactor is heated by a $1.7-\mathrm{kW}$ heater, which has the capability to heat the reaction environment up to $500^{\circ} \mathrm{C}$. The typical time required to heat $300 \mathrm{ml}$ of solution to $350^{\circ} \mathrm{C}$ is approximately $60 \mathrm{~min}$. The aqueous fluid and reaction gases are rapidly mixed inside the reactor by a magnetic-coupled stirrer. The reactor has a cooling coil that is used to cool down the reactor contents at the end of each experiment. The reactor and the majority of the ancillary equipment under pressure are contained inside a 1/4-in. steel barricade. Pressure indicators, temperature and stirrer controllers, and pressure and temperature alarms are located outside the barricade.

Gas samples are taken through a body wall port in the top of the reactor. The reactor and sample removal system are operated remotely after the reactor has been batch charged. The gas sample system employs a combination of a manually operated sampling valve and a pressure transducer on the sample loop to collect sample volumes. Typically, the sample loop is filled to a pressure of 50 psig. The sampling system allows the entire sample loop to be evacuated prior to taking a sample, avoiding contamination of the sample by previous samples. The system is equipped with an adsorbent column to collect any. water and other liquids in the samples. This column is weighed before and after experiments for a quantitative determination of the mass of water collected.

\section{Procedures}

The batch test conditions ranged from approximately $300^{\circ} \mathrm{C}$ to $400^{\circ} \mathrm{C}$ and 3000 to 4700 psig. Hold-times at a predetermined temperature ranged from 0.25 to $4 \mathrm{hr}$.

Approximately 200 to $300 \mathrm{ml}$ of liquid feed were introduced into the batch reactor. The system was then purged and pressure checked using argon gas. An overpressure of argon gas was always charged to the reactor prior to heatup (i.e., approximately 100 to 500 psig at room temperature). The reactor was then rapidly heated to the desired holdtemperature. The typical heatup time was approximately $1 \mathrm{hr}$. The reactor was then held at the targeted hold-temperature for the desired hold-time. Cooling water was turned on to the system to facilitate rapid cooldown of the reactor after the hold period. Cooldown of the reactor to approximately $100^{\circ} \mathrm{C}$ usually took about $0.5 \mathrm{hr}$. The reactor was then disassembled, and the liquid contents were submitted for analyses.

\section{Reagents}

The simulant used as feed in the batch tests was a nonradioactive caustic slurry (pH - 12.5) simulating Hanford Tank 101-SY. This simulant was chosen because Tank 101-SY is known to contain organic complexants. In the testing, 1 volume of simulated waste was diluted with 3 volumes of water to approximate dilution of the tank contents upon retrieval. The formulation of the 3:1 diluted simulant, using $\mathrm{Na}_{4} \mathrm{EDTA}$ as the organic source, is given in Table I. 


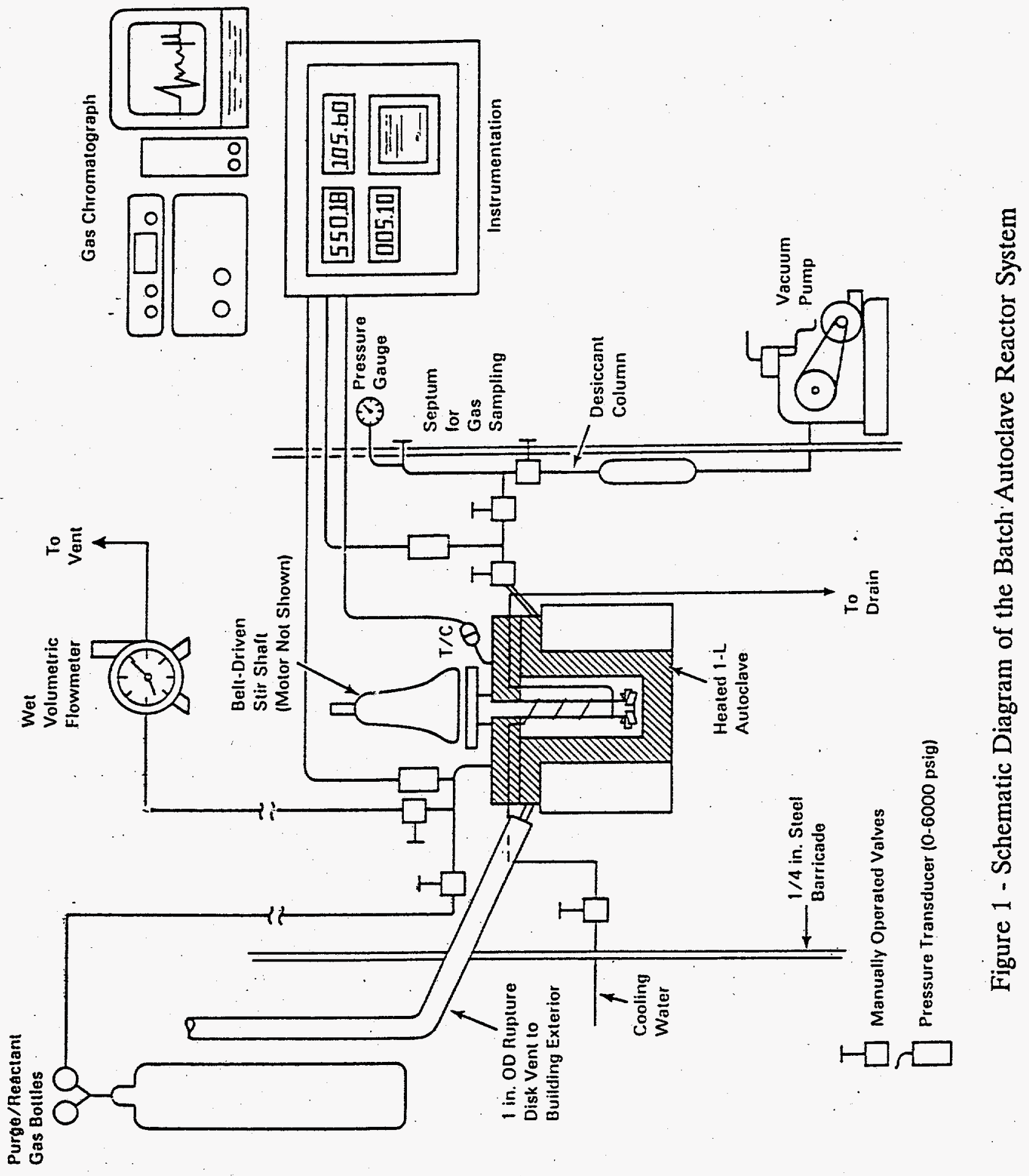


Table I - Hanford Tank 101-SY Simulant Formulation (3:1 diluted)

\begin{tabular}{|c|c|}
\hline Component & $\mathrm{Wt} \%$ \\
\hline $\mathrm{Na}_{4}$ EDTA & 1.67 \\
\hline $\mathrm{Na}_{3} \mathrm{PO}_{4}-12 \mathrm{H}_{2} \mathrm{O}$ & 0.89 \\
\hline $\mathrm{NaNO}_{2}$ & 5.47 \\
\hline $\mathrm{NaNO}_{3}$ & 4.53 \\
\hline $\mathrm{Na}_{2} \mathrm{CO}_{3}$ & 1.93 \\
\hline $\mathrm{Na}_{2} \mathrm{SO}_{4}$ & 0.21 \\
\hline $\mathrm{NaCl}$ & 0.45 \\
\hline $\mathrm{NaF} \quad-$ & $2.4 \times 10^{-2}$ \\
\hline $\mathrm{Ca}\left(\mathrm{NO}_{3}\right)_{2}-4 \mathrm{H}_{2} \mathrm{O}$ & $4.9 \times 10^{-2}$ \\
\hline $\mathrm{KNO}_{3}$ & 0.29 \\
\hline $\mathrm{ZnCl}_{2}$ & $1.5 \times 10^{-3}$ \\
\hline $\mathrm{CsNO}_{3}$ & $7.2 \times 10^{-4}$ \\
\hline $\mathrm{Sr}\left(\mathrm{NO}_{3}\right)_{2} *$ & $5.1 \times 10^{-5}$ \\
\hline $\mathrm{NaOH}$ & 2.04 \\
\hline $\mathrm{Cr}\left(\mathrm{NO}_{3}\right)_{3}-9 \mathrm{H}_{2} \mathrm{O}$ & 1.10 \\
\hline $\mathrm{Fe}\left(\mathrm{NO}_{3}\right)_{3}-9 \mathrm{H}_{2} \mathrm{O}$ & $7.0 \times 10^{-2}$ \\
\hline $\mathrm{Ni}\left(\mathrm{NO}_{3}\right)_{2}-6 \mathrm{H}_{2} \mathrm{O}$ & $2.4 \times 10^{-2}$ \\
\hline $\mathrm{NaAlO}_{2}-0.21 \mathrm{NaOH}-1.33 \mathrm{H}_{2} \mathrm{O}$ & 4.77 \\
\hline $\mathrm{H}_{2} \mathrm{O}$ & 76.49 \\
\hline Total & 100.00 \\
\hline
\end{tabular}

* In some cases significant amounts of $\mathrm{Sr}$ were introduced into the simulant as an impurity in the $\mathrm{Ca}\left(\mathrm{NO}_{3}\right)_{2}-4 \mathrm{H}_{2} \mathrm{O}$. $\mathrm{Sr}\left(\mathrm{NO}_{3}\right)_{2}$ represents the minimum amount of $\mathrm{Sr}$ present in the simulant.

The effects of several different organic compounds, expected to be found in Hanford tank waste, were evaluated in this testing: EDTA, HEDTA/EDTA (2/1 molar ratio), citrate, acetate, and formate. Thus, in some tests, these other organic compounds, rather than $\mathrm{Na}_{4}$ EDTA, were used to formulate the simulant. In all cases, however, the TOC content of the simulant was approximately 5000 to $5500 \mathrm{mg} / \mathrm{kg}$. Also, in all cases, the organic species were added as sodium salts. The total suspended solids content of the 3:1 diluted 101-SY simulant was typically between $1.5 \mathrm{wt} \%$ and $2 \mathrm{wt} \%$. After hydrothermal treatment, the suspended solids content remained unchanged (i.e., within analytical limits). 
Most of the tests were conducted using unfiltered 3:1 diluted 101-SY simulant. Some additional tests were conducted using 3:1 diluted 101-SY simulant that was filtered through $0.45-\mu \mathrm{m}$ filters. These tests were conducted using EDTA as the organic source.

\section{Analytical Techniques}

The feed and product samples obtained from the experiments were analyzed for strontium and TOC. Strontium analyses were conducted using a Perkin Elmer Model 5100 graphite furnace atomic absorption instrument with Zeeman background correction. Before these analyses were conducted, the feed and product samples were passed through a $0.45-\mu \mathrm{m}$ filter to remove any solids, and the filtrate was analyzed to determine the fate of the strontium upon hydrothermal treatment.

The TOC analysis was conducted using a Zertex-Dohrmann Model DC-80 carbon analyzer.

\section{Results and Discussion}

The results obtained from the batch tests included relative destruction rates for the organic species tested, relative strontium-complexing capabilities of the organics tested, and the effects of organic destruction on strontium removal.

Relative destruction rates of the various organics tested are illustrated in Figure 2. Acetate is by far the most difficult organic compound to destroy under the autogenous

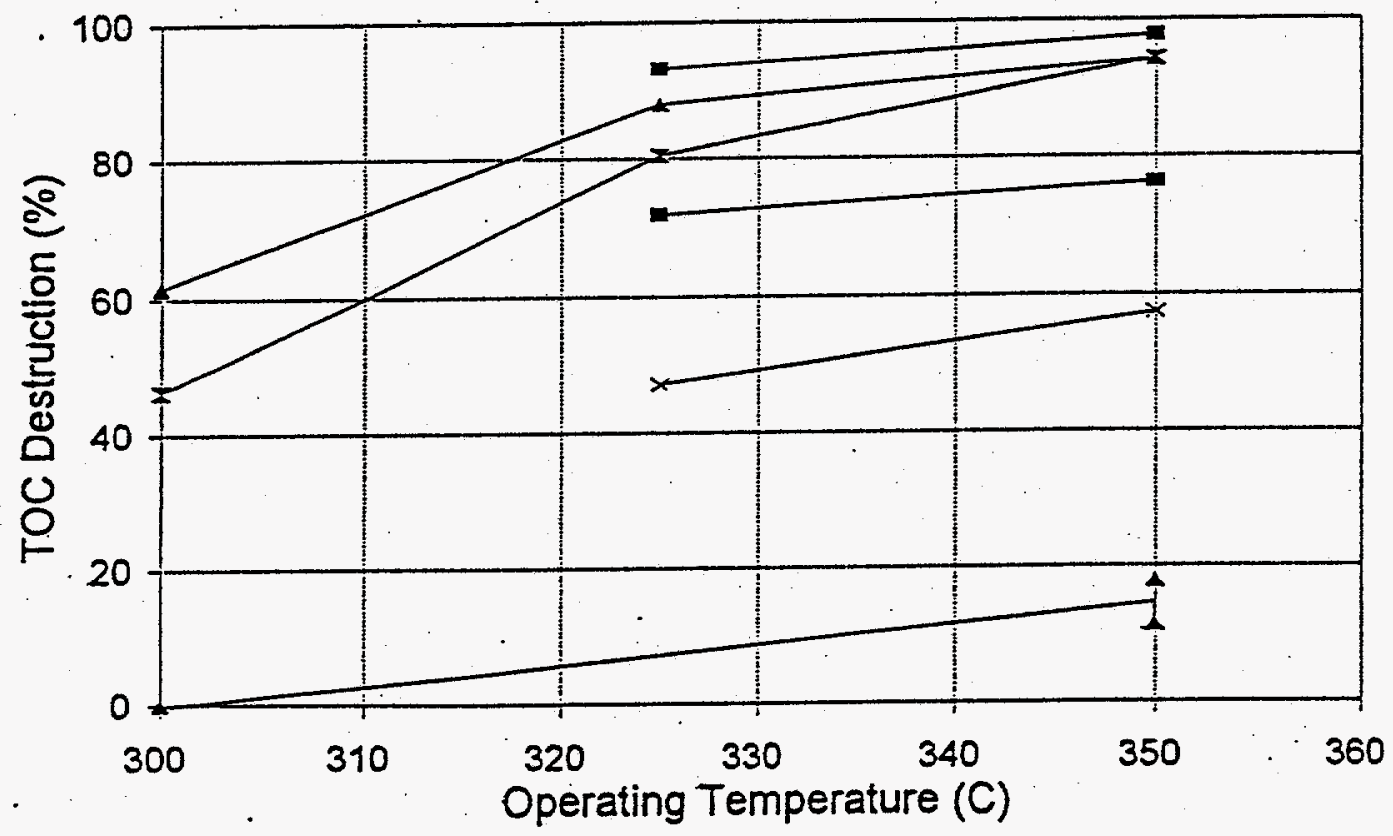

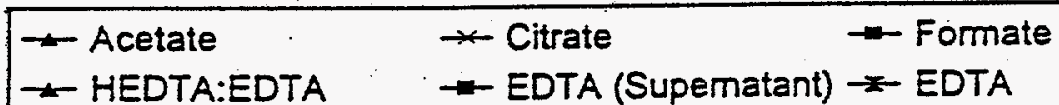

Figure 2 - Total Organic Carbon (TOC) Destruction Via Hydrothermal Treatment (1-hr batch test hold times) 
hydrothermal test conditions. Citrate is the next most difficult organic compound to destroy, followed by EDTA, HEDTA:EDTA (2:1 molar ratio), and formate. It is interesting to note that it was slightly more difficult to destroy the EDTA in the filtered simulant as compared to the unfiltered simulant. It is unknown at this point why this was the case, although it is suspected that the solids may have a slight catalytic effect.

The effect of organic destruction on the fate of strontium is given in Table II. In all of these cases, the liquid feed and product were passed through a $0.45-\mu \mathrm{m}$ filter upon completion of the tests, and the resulting filtrate was analyzed for strontium.

The first set of data given in Table II is for 3:1 diluted 101-SY simulant containing EDTA as the organic source. As can be seen, the TOC destruction ranges from $46 \%$ to $94 \%$, and the strontium removal from solution ranges from $94 \%$ to greater than $99 \%$. There is no definite trend relating TOC destruction to strontium removal. At the lowest TOC destruction (46\%), the strontium in solution was below the detection limits. As a result, further testing at lower temperatures and destruction efficiencies has been initiated to determine at what point strontium definitely appears in solution after hydrothermal treatment.- From the results presented in Table II, it can be said that 50\% TOC destruction (EDTA being the organic source) is sufficient to remove significant amounts of strontium from solution.

The second set of data given in Table II is for 3:1 diluted 101-SY simulant supernatant containing EDTA as the organic source. In these tests, the feed was passed through a $0.45-\mu \mathrm{m}$ filter prior to the test, and the filtrate was used as feed. Removal of solids from the feed prior to hydrothermal treatment was done because a solids/liquid separation process may be implemented upstream of the organic destruction process in the Hanford waste pretreatment facility. Significant amounts of strontium were removed from solution, and the TOC destruction levels were less than $77 \%$ in all cases.

A 2:1 molar ratio of HEDTA:EDTA was the organic source used to obtain the next set of data presented in Table II. For both conditions tested, greater than $99 \%$ of the strontium was removed from solution by hydrothermal processing of the simulant. In both cases, the TOC destruction levels were approximately $90 \%$.

Formate was the organic source used to obtain the next set of data given in Table II. Formate does not appear to complex strontium as well as some of the other organic compounds evaluated. The strontium remaining in solution varied between $<2.6 \mathrm{ppb}$ and $30 \mathrm{ppb}$ for greater than $90 \%$ TOC destruction.

The fifth set of data is for 3:1 diluted 101-SY simulant containing citrate as the organic source. Again, very good strontium removal from solution is attained for TOC destruction levels below $60 \%$.

The last set of data is for 3:1 diluted 101-SY simulant containing acetate as the organic source. Strontium is not complexed well by acetate, as illustrated by the initial strontium in the feed supernatant. As was illustrated in Figure 2, acetate is by far the most difficult organic to destroy; however, from a complexant destruction viewpoint it is unnecessary to destroy acetate to liberate strontium from solution or from the complexing organic compound. 
Table II - Total Organic Carbon Destruction/Strontium Results

\begin{tabular}{|c|c|c|c|c|}
\hline $\begin{array}{l}\text { Batch Test Conditions } \\
\text { (temp., hold-time) }\end{array}$ & $\begin{array}{l}\text { TOC Destruction } \\
(\%)\end{array}$ & $\begin{array}{l}\text { Initial } \mathrm{Sr} \text { in Feed } \\
\text { Supernatant }(\mathrm{ppb})\end{array}$ & $\begin{array}{l}\text { Final Sr in Product } \\
\text { Supernatant }(\mathrm{ppb})\end{array}$ & $\begin{array}{l}\text { Sr Removed From } \\
\text { Supernatant }(\%)\end{array}$ \\
\hline \multicolumn{5}{|c|}{ 3:1 DILUTED 101-SY SIMULANT, EDTA AS ORGANIC SOURCE } \\
\hline $297^{\circ} \mathrm{C}, 1 \mathrm{hr}$ & 46.3 & 302 & $<2.2$ & $>99.3$ \\
\hline $325^{\circ} \mathrm{C}, 1 \mathrm{hr}$ & 80.5 & 384 & 9.0 & 97.7 \\
\hline $350^{\circ} \mathrm{C}, 0.25 \mathrm{hr}$ & 78.8 & 321 & $5.6,<2.0$ & $98.3,>99.2$ \\
\hline $350^{\circ} \mathrm{C}, 1 \mathrm{hr}$ & 94.4 & 298 & 18.1 & 93.9 \\
\hline $350^{\circ} \mathrm{C}, 1 \mathrm{hr}$ & 94.4 & 246,240 & $<2.5,<2.0$ & $>99.0,>99.2$ \\
\hline \multicolumn{5}{|c|}{ 3:1 DILUTED 101-SY SIMULANT (SUPERNATANT), EDTA AS ORGANIC SOURCE } \\
\hline $325^{\circ} \mathrm{C}, 1 \mathrm{hr}$ & 71.8 & $373^{*}$ & $<2.3$ & $>99.4$ \\
\hline $349^{\circ} \mathrm{C}, 0.25 \mathrm{hr}$ & 69.2 & 373 & 7.3 & 98.0 \\
\hline $325^{\circ} \mathrm{C}, 1 \mathrm{hr}$ & 71.8 & 373 & $<2.3$ & $>99.4$ \\
\hline \multicolumn{5}{|c|}{$\begin{array}{l}\text { 3:1 DILUTED 101-SY SIMULANT, HEDTA:EDTA (2:1 MOL:MOL) } \\
\text { AS ORGANIC SOURCE }\end{array}$} \\
\hline $325^{\circ} \mathrm{C}, 1 \mathrm{hr}$ & 88.1 & $822^{*}$ & $<8.2$ & $>99.0$ \\
\hline $355^{\circ} \mathrm{C}, 1 \mathrm{hr}$ & 94.4 & 822 & $<8.2$ & $>99.0$ \\
\hline
\end{tabular}


Table II - (contd)

\begin{tabular}{|c|c|c|c|c|}
\hline $\begin{array}{l}\text { Batch Test Conditions } \\
\text { (temp., hold-time) }\end{array}$ & $\begin{array}{l}\text { TOC Destruction } \\
(\%)\end{array}$ & $\begin{array}{l}\text { Initial Sr in Feed } \\
\text { Supernatant }(\mathrm{ppb})\end{array}$ & $\begin{array}{l}\text { Final Sr in Product } \\
\text { Supernatant (ppb) }\end{array}$ & $\begin{array}{l}\text { Sr Removed From } \\
\text { Supernatant }(\%)\end{array}$ \\
\hline \multicolumn{5}{|c|}{ 3:1 DILUTED 101-SY SIMULANT, FORMATE AS ORGANIC SOURCE } \\
\hline $328^{\circ} \mathrm{C}, 1 \mathrm{hr}$ & 93.3 & 50.9 & 29.5 & 79.8 \\
\hline $353^{\circ} \mathrm{C}, 1 \mathrm{hr}$ & 97.9 & 15.6 & $<2.6$ & $>83.0$ \\
\hline \multicolumn{5}{|c|}{ 3:1 DILUTED 101-SY SIMULANT, CITRATE AS ORGANIC SOURCE } \\
\hline $325^{\circ} \mathrm{C}, 1 \mathrm{hr}$ & 47.2 & $771^{*}$ & 19.1 & 97.5 \\
\hline $352^{\circ} \mathrm{C}, 1 \mathrm{hr}$ & 57.4 & 771 & $<8.2$ & $>99.7$ \\
\hline \multicolumn{5}{|c|}{ 3:1 DILUTED 101-SY SIMULANT, ACETATE AS ORGANIC SOURCE } \\
\hline $303^{\circ} \mathrm{C}, 1 \mathrm{hr}$ & 0 & $2.8^{*}$ & $<2.2$ & $>21$ \\
\hline $350^{\circ} \mathrm{C}, 1 \mathrm{hr}$ & 14.7 & 2.8 & 8.3 & $\cdots$ \\
\hline $351^{\circ} \mathrm{C}, 4 \mathrm{hr}$ & 88.9 & 2.8 & 7.7 & --- \\
\hline $411^{\circ} \mathrm{C}, 1 \mathrm{hr}$ & 97.9 & 2.8 & 7.3 & $\cdots$ \\
\hline
\end{tabular}

*: One composite feed sample taken for that simulant. 


\section{Conclusions}

The following conclusions were drawn from the data obtained from batch testing with a caustic Hanford tank waste simulant:

1. The ease of TOC destruction via autogenous hydrothermal destruction is in the following order: Formate $>$ HEDTA/EDTA $>$ EDTA $>$ Citrate $>>$ Acetate.

2. Complete or near-complete destruction of complexants such as EDTA does not appear to be necessary to release strontium from solution and/or from the complexant. Fifty percent TOC destruction (EDTA as the organic source) decreases the strontium concentration in solution from $300 \mathrm{ppb}$ to $<2 \mathrm{ppb}$ :

3. EDTA, HEDTA/EDTA, and citrate complex (and solubilize) strontium, while formate and acetate do not complex strontium to an appreciable extent.

4. Acetate is by far the most difficult organic compound to destroy via low-temperature hydrothermal treatment. However, destruction of acetate is not necessary to enhance strontium removal because it does not complex and solubilize strontium.

In light of these observations, it appears that hydrothermal destruction of the organic complexants is an effective way to remove strontium from the highly alkaline solutions that are characteristic of Hanford tank waste. This would be beneficial for separating radioactive streams (i.e., streams containing ${ }^{90} \mathrm{Sr}$ ) into low-level and high-level waste streams. Testing with actual Hanford waste has been initiated to verify these findings, as well as to determine the fate of other radioactive constituents such as ${ }^{241} \mathrm{Am}$ upon hydrothermal treatment.

\section{Acknowledgments}

Pacific Northwest Laboratory is operated for the U.S. Department of Energy by Battelle Memorial Institute under Contract DE-AC06-76RLO 1830.

\section{References}

1. A. J. Schmidt et al., "Preliminary Conceptual Design for the Destruction of Organic/Ferrocyanide Constituents in the Hanford Tank Waste with Low-Temperature Hydrothermal Processing" (Report PNL-SA-23181, Pacific Northwest Laboratory, 1993).

2. P. Dell'Orco et al., "Kinetics of Nitrate and Nitrite Reduction Reactions in Hydrothermal Systems" (Report LA-UR-93-3146, Los Alamos National Laboratory, 1993).

3. B. R. Foy et al., "Kinetics of Organic Oxidation by Nitrate in Hydrothermal Systems" (Report LA-UR-93-3147, Los Alamos National Laboratory, 1993). 
4. L. J. Sealock, Jr. et al., "Chemical Processing in High-Pressure Aqueous Environments. 1. Historical Perspective and Continuing Developments," Ind. Eng. Chem. Res., 32 (1993), 1535-1541.

5. D. C. Elliott, L. J. Sealock, Jr., and E. G. Baker, "Chemical Processing in HighPressure Aqueous Environments. 2. Development of Catalysts for Gasification," Ind. Eng. Chem. Res., 32 (1993), 1542-1548.

6. D. C. Elliott, L. J. Sealock, Jr., and E. G. Baker, "Chemical Processing in HighPressure Aqueous Environments. 3. Batch Reactor Process Development Experiments for Organics Destruction," Ind. Eng. Chem. Res., 33 (1994), 558-565.

7. D. C. Elliott et al., "Chemical Processing in High-Pressure Aqueous Environments. 4. Continuous-Flow Reactor Process Development Experiments for Organics Destruction," Ind. Eng. Chem. Res., 33 (1994), 566-574.

8. T. M. Hohl et al., "Synthetic Waste Formulations for Representing Hanford Tank Waste" (Report WHC-SD-WM-TI-549, Rev. 0, Westinghouse Hanford Company, 1993). 